\title{
Modern Dissemination Opportunities to Keep up with Rapidly Changing Field
}

\author{
Dr. Jenny Grant Rankin
}

American Mensa

\begin{abstract}
New approaches in education can only have maximum global impact if these modern approaches are shared widely and well. As eLearning and other education areas evolve, related research findings must be shared effectively for all students to benefit from new discoveries in the field. Just as rapidly changing technology and media offer new opportunities in education, they also offer new opportunities for scientists, researchers, educators, and students to exchange ideas and solutions. This paper includes an examination of new education research dissemination opportunities available today so that new discoveries and information can more immediately inform education practices worldwide. Such opportunities for disseminating new approaches to local and global audiences include social media tools, expert databases used by journalists, branding tools, reporter query services, mainstream and high-exposure speaking formats like TED Talks, podcasts and other broadcasts, speaker databases, and more. Resources available to women and traditionally marginalized and underrepresented groups are also addressed so that more diverse perspectives are represented in field dialogue. The paper also covers practical issues such as time management, balancing projects, and higher education institution parameters.
\end{abstract}

Keywords: disseminate; exposure; knowledge management; partnership; press 